\title{
Intestinal Stoma Prolapse and Surgical Treatments of This Condition in Children: A Systematic Review and a Retrospective Study
}

\author{
Prince Johnson \\ University of Oslo, Nesoddtangen, Norway \\ Email: prince.johnson.studmed@outlook.com
}

How to cite this paper: Johnson, P. (2016) Intestinal Stoma Prolapse and Surgical Treatments of This Condition in Children: A Systematic Review and a Retrospective Study. Surgical Science, 7, 400-426.

http://dx.doi.org/10.4236/ss.2016.79057

Received: August 4, 2016

Accepted: September 16, 2016

Published: September 20, 2016

Copyright $\odot 2016$ by author and Scientific Research Publishing Inc. This work is licensed under the Creative Commons Attribution International License (CC BY 4.0).

http://creativecommons.org/licenses/by/4.0/

\begin{abstract}
Background: An intestinal stoma is a surgical opening of the intestine, mostly sutured to the anterior abdominal wall. Stoma prolapse is one of the common complications of stoma. A significant number of stoma prolapse patients require surgical correction. Aim: The first part of this thesis is a literature review of intestinal stoma prolapse and its surgical treatments. The second part is an evaluation of the effect of surgical treatments of this condition on children at OUS-R. Methods: Literature-A literature search was performed. Fifty-seven English-language studies were selected. Methods: Patients evaluation: Design, Setting, and Participants-A retrospective review of pediatric patients ( $<13$ years) surgically treated for intestinal stoma prolapse at OUS-R. Results: Literature-Incidence of intestinal stoma prolapse for children varies from $8.1 \%$ to $25.6 \%$. Many proposed surgical repair procedures for stoma prolapse are available and vary from being ineffective to $100 \%$ effective. Results: Patients evaluation at OUS-R-From 2001 to 2013, 14 of the 304 children with stoma (4.6\%), experienced stoma prolapse. Nine stoma prolapse were surgically corrected: Median age at stoma formation for the 9 patients was 1.7 years. Surgical procedures and success rate: Median 2, range 1 - 9 operations/person; varies from being ineffective to $50 \%$ effective. Conclusion: Limited data suggests stoma prolapse repair is a surgical challenge. Thus, preferably when possible, closure of the stoma would be most suitable. Incidence of stoma prolapse in our series of pediatric patients at Oslo University Hospital is lower than most published incidence in the pediatric medical literature.
\end{abstract}

\section{Keywords}

Stoma, Children, Neonates, Stoma Complications, Stoma Prolapse, Surgical Management 


\section{Introduction}

\subsection{Historical Background}

It is believed that the first colostomy was performed in 1783 by a Parisian surgeon, Dubois, on a 3-day old child with an imperforate anus, but the child died on the 10th postoperative day [1]. In 1793, Duret, a naval surgeon performed the second documented colostomy, albeit the first successful (loop sigmoid) colostomy, also in the treatment of imperforate anus, in a 3-day-old infant [1]. The stoma constructed by Duret, though successful, resulted in a prolapse [1] [2].

\subsection{Stoma}

An intestinal stoma is a surgical opening of the intestine, mostly sutured to the anterior abdominal wall. Stomas are formed on elective or emergent basis. Surgical methods in which stomas are formed are ended in the suffix-ostomy and start with a prefix of the area being operated on. The procedure involves division, usually in the distal part of the small intestine, the ileum, and of the large intestine, the colon. The main reasons for performing stoma is to divert faecal stream, bowel decompression, protecting gut anastomosis, or a combination of these indications. Unlike most adults, stomas in children are often a temporary procedure undertaken as part of the surgical management of congenital malformations and acquired conditions of the intestinal tract [2] [3]. Anorectal malformation and Hirschsprung's disease are among the major underlying diagnosis for stoma in infants and children [2] [3].

The placement of a stoma for the diversion of intestinal flow in children, particularly in neonates, may present problems because a much dilated bowel must be brought through a thin abdominal wall, especially in Hirschsprung's disease patients [2]. When improperly formed a stoma may result in a complication such as prolapse, which can undermine or delay the treatment of these conditions. Stoma prolapse, a condition in which the intestine invaginates and bulges through the stoma more than $6 \mathrm{~cm}$, measured vertically above the skin [4]. It is one of the most common complications of stoma that can affect the patient not just physically but, also psychologically [5] [6]. Even with a careful and proper technique stoma prolapse do occur.

The first part is a literature review of intestinal stoma prolapse, its incidence, possible risk factors and its surgical treatments. The second part evaluates the effect of surgical treatments of this condition on children at Oslo University Hospital, Rikshospitalet (The National Hospital) OUS-R. In order to avoid excessive tautology, the terms stoma and prolapse in this thesis basically refer to intestinal stoma and intestinal stoma prolapse only. This thesis is different from most publications so far, as it comprises both literature review and patient data; and succinctly sheds light on plethora of surgical methods to correct stoma prolapse.

\subsection{Institutional Experience}

Oslo University Hospital, Rikshospitalet (The National Hospital), formed in 1826, has 
highly experienced personnel. It is a very well specialized university hospital with special tasks in research and the development of first-hand methods of treatment, and covers the entire country in diverse fields, comprising organ and bone marrow transplants, advanced neurosurgery, care and treatments of children with congenital malformations and patients with rare disorsers. Roughly $60 \%$ of the patients admitted to the national hospital are referred from other hospitals in Norway for more specialized and advance investigations and treatment.

\section{Method}

\subsection{Literature Review}

A literature search was performed with Boolean operators, using PubMed and Google scholar database for all the relevant studies, reviews, editorials and letters/correspondences; using internet-based engines. The keywords used for the search were stoma, colostomy, ileostomy, stoma prolapse, prolapse and complications, and with the terms children, child, infants, neonates, pediatric and surgical management of stoma prolapse in different logical arrangements to find an appropriate literature. The bibliographies of the appropriate studies, reviews, editorials and letters/correspondences were examined, cross-referenced and reviewed by the author.

The search was further limited by restrictions to intestinal stomas and humans, thus excluding many studies. Similarly, attention was given to nursing journals, due to the fact that few studies have been done in surgical treatments of stoma prolapse, especially in children. The search was thus, not limited to specific date and age; this means articles on adults, some small series ( $<10$ patients), some older articles describing the pioneering, novel and innovative surgical approaches to deal with stoma prolapse and recurrences were included in this thesis. Despite the contemporary trend towards methodical data synthesis in secondary research, it was thought that the unavailability of highquality studies such as level 1 evidence studies; demonstrating research results addressing clinical outcomes and meeting a wide-ranging set of quality criteria, would not allow for the use of such formal methodology. Thus, what was deemed to be level 2-5 evidence studies; provided by the Centre for evidence based medicine Oxford, were included. The search was not limited to studies with abstracts. No other formal or qualitative selection criteria were used except, for studies describing surgical management where stoma prolapse was necessary for inclusion. Fifty-seven of 406 potentially relevant English-language studies were selected for the literature review (Figure 1(A)).

\subsection{Patients Evaluation: Data Source, Patients Identification, Inclusion/Exclusion Criteria, Data Classification and Registered Parameters}

The second part of this thesis focuses on a retrospective review of pediatric patients surgically treated for intestinal stoma prolapse at Oslo University Hospital-The National Hospital (OUS-R) from 01. 01. 2001 to 29. 05. 2013. The patients were first identified by going through the operation protocol at the pediatric surgical ward of OUS-R for all, 


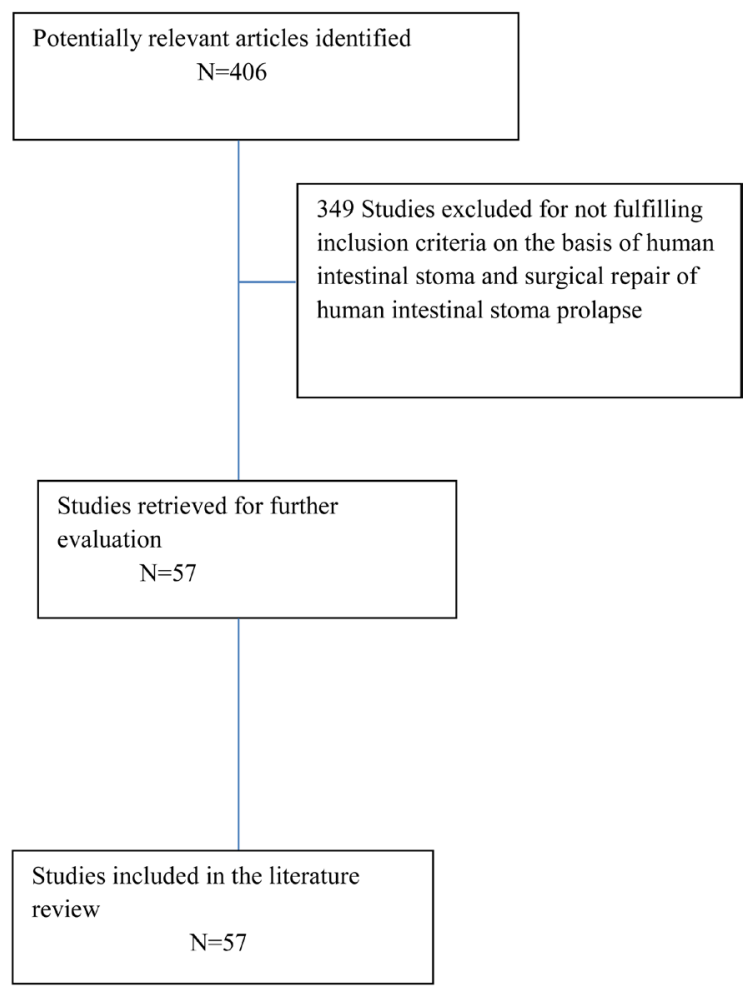

(A)

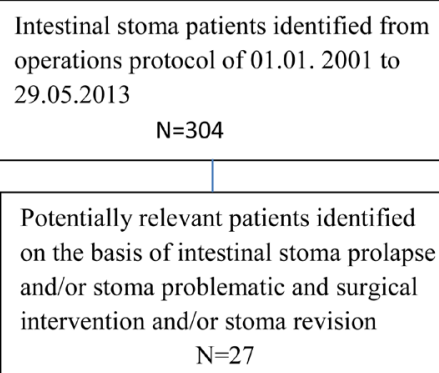

Potentially relevant patients identified on the basis of intestinal stoma prolapse and/or stoma problematic and surgical intervention and/or stoma revision $\mathrm{N}=27$

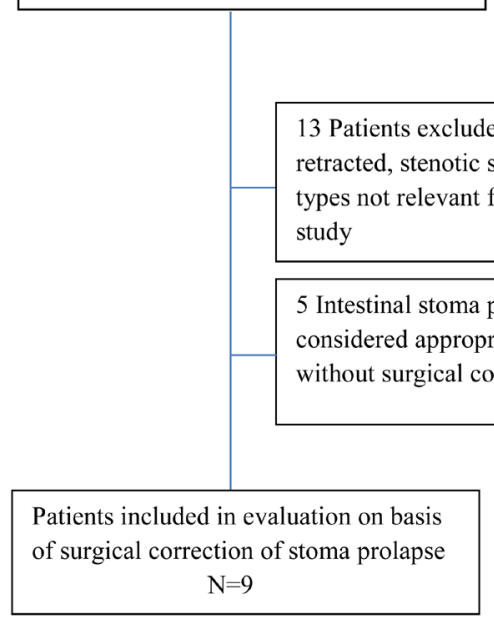

(B)

Figure 1. Flow diagrams of study and patients selection process. (A) Literature; (B) patients data at OUS-R. 
different types of pediatric patients operated on during the same period of time to first of all, identify all those with intestinal stoma (304). Twenty-seven patients; 14 with intestinal stoma prolapse, 6 with stoma problematic and 7 with revised stoma were identified. Thirteen patients out of the 27 were excluded; 5 with stenotic stoma without prolapse, 4 with retracted stoma, 2 parastomal hernia and 2 stoma with granulations at the stoma skin junction.

A further 5 intestinal stoma prolapse were considered appropriate for closure without surgical correction. Finally selecting only 9 patients, those surgically treated for intestinal stoma prolapse for the study. A retrospective review of the medical records via DIPS electronic journal system at OUS-R of those 9 patients surgically treated for intestinal stoma prolapse then forms the basis for the patients data (Figure 1(B)). A standardized registration form (Appendix) was made and the following parameters were registered. Age at stoma formation, gender, body weight at stoma formation, underlying diagnosis, type of stoma by bowel location, stoma type by construction, stoma type by intended duration, emergent status at stoma formation, preoperative marking, stoma directed within rectus muscle, time of prolapse, recurrences after surgical repair, time of recurrences and type of surgical repair methods employed. All patients with intestinal stoma prolapse closed at first attempt, or not surgically treated were not included in the patients evaluation.

\section{Results-Literature Review}

\subsection{Definitions and Classifications}

Stomas may be classified according to whether they are temporary or permanent, emergent or electively constructed, where they are located and how they are constructed.

\subsection{Emergent and Elective}

Stomas may also be classified according to whether they are emergently or electively constructed, can have implication on complications such as prolapse and wound infection.

\subsection{Temporary and Permanent Stomas}

Temporary stoma is meant to be put down, but allows a portion of the intestine to rest or heal for a short period of time, in contrast to a stoma meant to be permanent, which is not common in children.

\subsection{Anatomical Stomas}

Anatomical stomas may be classified according to the anatomical location the opening is formed. Examples include ileostomy, ascending colostomy, transverse colostomy, descending and sigmoid colostomy

\subsection{Constructional Stomas and Common Types of Intestinal Stomas}

Constructional classification says something about how the stoma is formed. There are 
two major types: loop and divided stoma. In loop stoma an entrance is made without completely separating the bowel, whereas in divided the bowel is absolutely divided and its continuation brought to a definitive end. The divided stomas may be further categorized as double-barrel or end stomas, depending on how the distal and the proximal limbs are placed. In double-barrel stoma, the proximal and distal limbs of the stoma may or may not be brought out through the same fascial opening, the limbs if brought out separated by a skin incisions, is termed "skin bridge, whereas in the end stoma, the proximal limb is used to evacuate faeces and flatus, and the distal limb if available is closed and placed back in to the abdominal cavity or placed at the skin level as a flushed closed stoma.

\subsection{Indications for Intestinal Stoma Formation}

The most common indications for the formation of stoma in children are Hirschsprung's disease, anorectalmal formations, necrotizing enterocolititis, meconium ileus/ distal intestinal obstruction, colon perforation, colonic atresia and intussusception [2][4] [7] [8]. Generally, clinical scenarios that may warrant construction of a stoma include; volvulus, cystic fibrosis, bowel obstruction, bowel stricture, rectovaginal fistula, fecal incontinence, traumatic rectal injuries, colonic and small bowel injuries, such as perforation from trauma or medication, iatrogenic, atresia, complicated perianal fistulas, peritonitis, anastomotic leak, hemodynamic instability, bowel cancer/tumour, Crohn's colitis, ulcerative colitis, neurological disorder affecting the bowel motility or/ andinternal and external anal sphincter, familial polyposis, carcinomatosis, villous adenoma, irradiation colitis, irradiation fistula, Fournier's gangrene [2] [3] [7]-[10].

\subsection{Intestinal Stoma Complications}

Many intestinal stoma complications occur within days after the stoma formation, and are mainly related to technical failures [11]. Early complications are defined as those occurring within one month of stoma construction [10]. The most common early complications are skin irritation, pain associated with poor stoma location, necrosis and retraction [3] [10]-[13]. The most common late complications are prolapse, stenosis and parastomal hernia [3] [10] [12] [13]. Intestinal stoma prolapse and skin excoriations are the frequently occurring complications of intestinal stoma 14. Complications differ with type of intestinal stoma, with the least complications occurring in patients with end stomas [11] [12]. Loop ileostomies are associated with the highest complication rates [11] [12]. The following risk factors appear to increase the rate of intestinal stoma complications. Absence of preoperative markings, height of stoma $<10 \mathrm{~mm}$, emergent stoma formation, comorbid medical illnesses and lack of proper surgical technique [11] [15] [16]. Table 1 shows analysis of specific complications for each adult intestinal stoma type as observed by some authors, and Table 2 shows published data on incidence of intestinal stoma complications in adults and children according to other authors. Steps to minimize the risk of occurrence of intestinal stoma complications include appropriate siting of the stoma; poor sited stoma increases the risk of complications [10] [17]. 
Table 1. Analysis of specific complications for each adult stoma type, percentage in brackets [15].

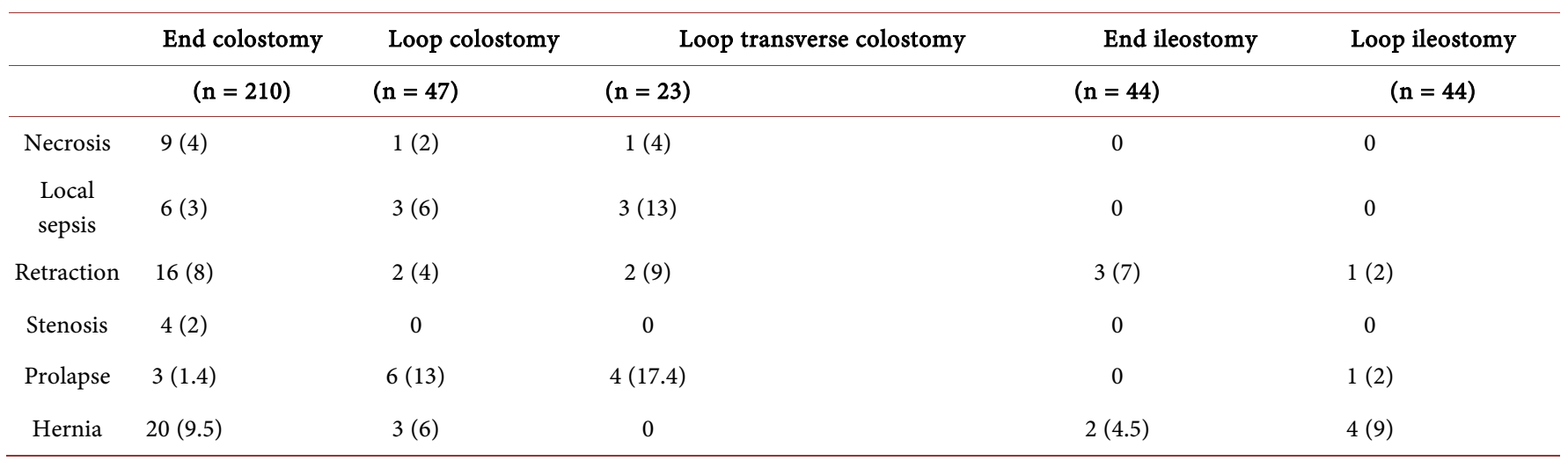

Table 2. Incidence of stoma complications [\%] in adults population and only children where specified ([Incidence; first reference/incidence; second reference]) [10] [15] [18]-[20].

\begin{tabular}{|c|c|c|c|c|c|}
\hline & Stoma $[18]$ & Stoma $[18]$ & Ileostomy [15] [19] & Colostomy [15] [19] & Children [20] \\
\hline Parastomal hernia & 14.1 & 1.18 & $6.7 / 22$ & $7.5 / 40$ & 1 \\
\hline Bleeding & 12.8 & 0.74 & $0 / 0$ & $0 / 0$ & $1-10$ \\
\hline Ischemia & 8.2 & $0 / 0$ & $0 / 0$ & $0 / 0$ & $<1$ \\
\hline Prolapse & 5.4 & 1.73 & $11 / 1$ & $3.4 / 2$ & $12-24$ \\
\hline Stenosis & 4.3 & 1.67 & $2 / 0$ & $1.5 / 1$ & $3 / 0$ \\
\hline Necrosis & 0 & 0.37 & $0 / 0$ & $3.8 / 0$ & $<1$ \\
\hline
\end{tabular}

Appropriate siting of the stoma should be determined preceding elective and emergency surgical procedures by a stoma nurse. In the case of an emergent procedure with limited time, the ideal site is two-thirds along the line from the anterior superior iliac spine (ASIS) and the umbilicus or a rhombus could be drawn from the pubis symphysis to the umbilicus via the ASIS on both sides. This rhombus should then be bisected by a transverse line at the ASIS forming 2 triangles. A location at or slightly above the center of the upper triangle would be the ideal site [11] [21]. The stoma should be in good sight to the patient standing, sitting, bending and should be placed in areas without skin folds [21]. Furthermore, scars, bony prominences, and the umbilicus should be avoided [21]. Necrosis of the stoma is usually an outcome of either venous congestion from extreme tension, arterial insufficiency from excessive mesenteric dissection, or a constricted fascial aperture. Adequate mobilizations of the bowel and preservation of the blood supply to the stoma are therefore vital factors for avoiding this complication.

Stomal retraction is defined by some authors as a stoma that is at least $0.5 \mathrm{~cm}$ below the skin surface [11] [22]. Retraction leads to leakage and difficulties with stomal bag adherence, leading to peristomal skin irritation. The best approach to inhibiting stoma 
retraction and skin irritation is to construct a stoma at least $10 \mathrm{~mm}$ high for colostomies and 2 to $3 \mathrm{~cm}$ high for ileostomies [11] [23]. Peristomal skin irritation presents early, and can be a long-term problem or may present late, the incidence of late skin irritation reported by some authors was $6 \%$ [10]. A parastomal hernia is a type of incisional hernia that permits protrusion of the intestine, and sometimes with abdominal tissue through the abdominal wall/fascia defect created during stoma formation or immediately adjacent to the stoma. A proper surgical technique is the best approach to reduce the risk of parastomal hernia [16]. Stomal stenosis refers to narrowing of the lumen of the stoma through the fascia or obstruction of the stoma outlet secondary to tightness of the mucocutaneous junction. Stomal stenosis is more likely to develop months after formation but, sometimes it may occur in the early postoperative period, early stenosis as reported by some authors was $0.25 \%$ [10]. The optimal approach to reduce the risk of stenosis is therefore to create an adequate opening through the abdomen to accommodate the bowel.

\subsection{Intestinal Stoma Prolapse}

Stoma prolapse, as mentioned, is the protrusion of the invaginated intestine through the stoma more than $6 \mathrm{~cm}$, measured vertically above the skin [4]. Arumugam et al. however, defined stoma prolapse as an increase in stoma size after maturation, requiring change in the size of appliance or requiring surgical treatment [22]. No separate definition of stoma prolapse for children was found in the literature. Stoma prolapse may be characterized as either fixed or sliding [24] [25]: In the fixed stoma prolapse, the distal end goes far above the abdominal wall with the length of the prolapse steady [25]. A sliding stoma prolapse also involves the protrusion of the averted intestine, either ileum or colon through the stoma site itself [25]. However, unlike a fixed prolapse, the length of the sliding prolapsed intestine changes spontaneously according to the extent of intra-abdominal pressure [25] [26]. The characterization is useful, as it may help determine the appropriate type of surgical repair for stoma prolapse [24].

\subsection{Etiology}

Prolapse may also occur when a skin opening is made to accommodate dilated bowel which, upon shrinking leaves a loose stoma [2]. According to Pena et al. stoma may prolapse when the stoma is placed in a mobile portion of the bowel such as the sigmoid or transverse colon (Figures 2(A)-(C)) [8]. Spotting this makes the complication avoidable; by forming stoma in fixed segments of the bowel or by fixing the mobile bowel [8].

The following risk factors, nearly similar to the risk factors for general stoma complications are also likely to predispose to stoma prolapse: Absence of preoperative markings, emergent stoma formation, comorbid medical illnesses, vigorous sporting activities, weak fascia, incision as opposed to excision of the fascia; as this may weakens the abdominal wall and predisposes to stoma prolapse, failure of mesenteric or bowel fixation, high intestinal motility and redundancy, redundant mesentery, minimal intes- 


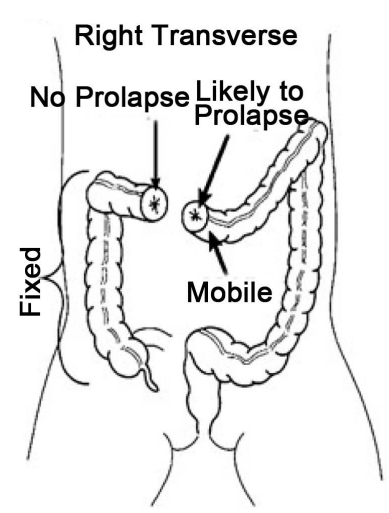

(A)

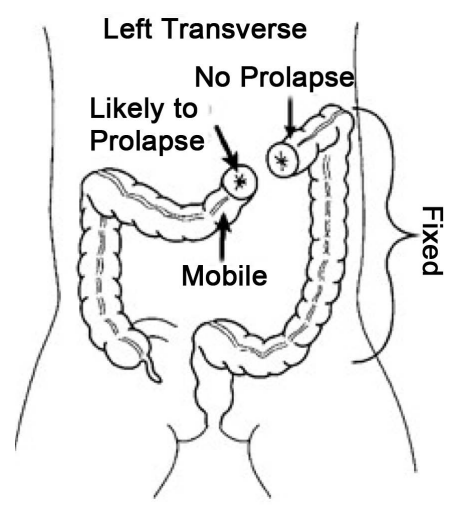

(B)

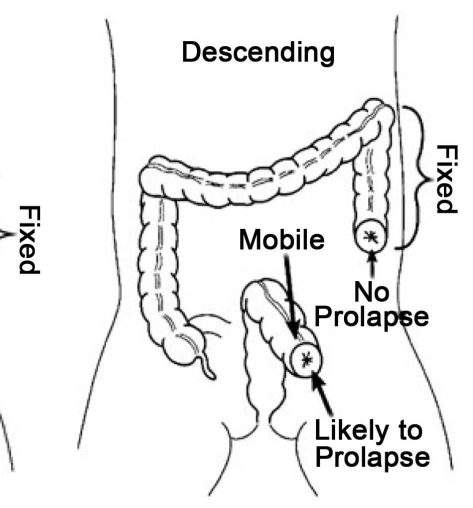

(C)
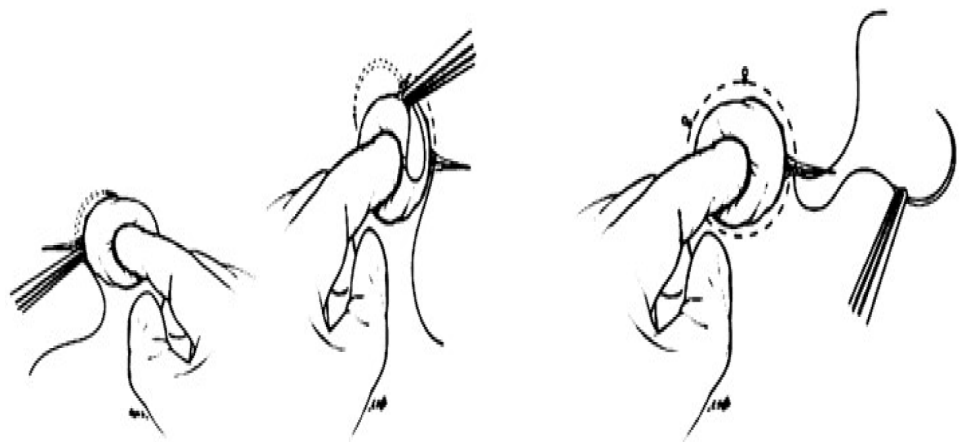

(D)
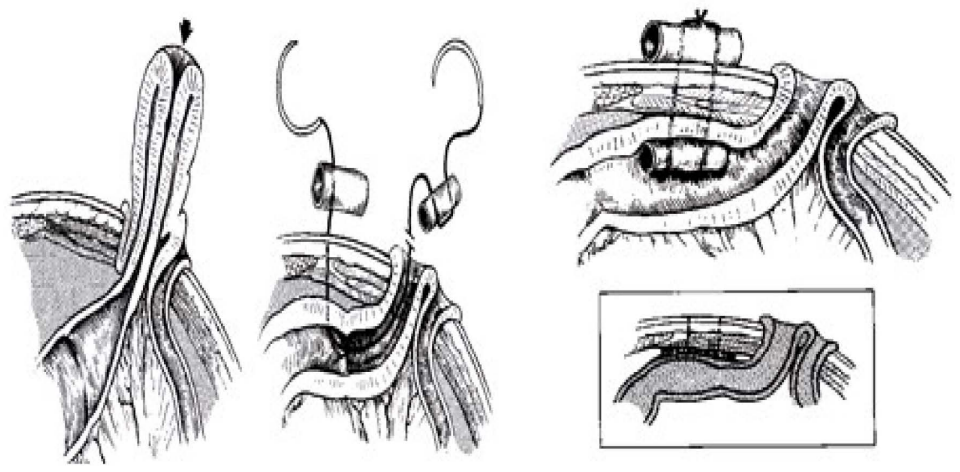

(E)
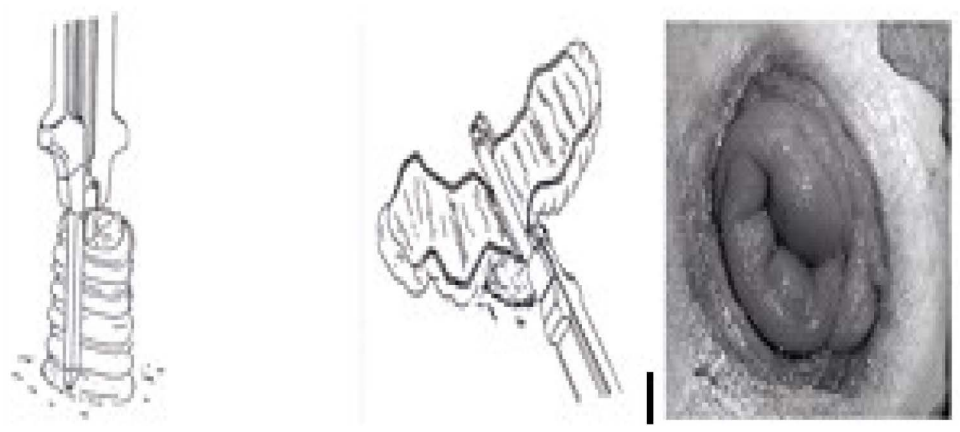

(F)

Figure 2. (A)-(C) Mobile and fixed parts of the colon. Pena et al. [8]; (D) purse string procedure [7] [41]; (E) U-stitch procedure. Gauderer [42]; (F) correction of stoma prolapse. Hata et al. [43]. 
tinal fixation, thinness and hypotonicity of the abdominal wall, contraction of exteriorized bowel causing a disproportionately large fascial defect and type of stoma; loop with higher incidence than end [2] [4] [10] [12] [13] [27] [28]. Circumstances that increase intra-abdominal pressure probably predispose to stoma prolapse such as chronic coughing, obesity, frequent straining, crying and screaming especially neonates, infants and children [4] [8] [13] [17] [26] [28]. Constructing of an oversized abdominal wall aperture predisposes to prolapse.

\subsection{Complications}

The protrusion of the stoma, particularly if it occurs together with a parastomal hernia may lead to problems with proper fitting of the stoma appliances. A prolapsed stoma may be affected by dryness or by an ill-fitting appliance which may lead to mucosal ulceration; pain or bleeding as a result of skin excoriation [29]. Weaver et al. observed that 3 of 8 patients with ileostomy prolapse experienced damage to the stoma due to its long protruded nature; causing ulceration and bleeding in 2 [27]. Prolapsed stoma may even give rise to abdominal problems such as pain [30]. The prolapsed bowel itself may be disposed to edema, leakage and strain, including mucosal ulceration and further bleeding. In clinical scenario of obstruction from strangulation, stoma prolapse may even lead to possible peritonitis [29].

\subsection{Incidence}

The incidence of stoma prolapse is not static but changes subject to among other things, its intestinal location, primary diagnosis, length of follow-up and stoma type. The most commonly published incidence of stoma prolapse in adults population ranges from $2 \%$ to $16 \%$, median $5.4 \%$ [6] [10] [14] [15] [31]-[35].

The incidence of stoma prolapse for ileostomy and colostomy was $3 \%$ and $2 \%$, respectively according to Fleshman et al. after evaluating 16,740 adults patients with stoma [13]. In a survey of 1616 adults intestinal stomas formed at John H. Stroger, Jr. Hospital, over a 20 -year period, Park et al. observed an overall $2 \%$ incidence of stoma prolapse [10]. Similarly, Garlock et al. also observed 2\% incidence of stoma prolapse in 173 adults patients, albeit a little older article [36]. Analysis of prolapse for each stoma type in adults observed by Harris et al. in a study of 345 stomas, is shown under intestinal stoma complications, Table 1 [15].

Çiğdem et al. retrospectively studied 473 children who underwent a colostomy, observing a $20.5 \%$ incidence of prolapse, the second most common complication in the series behind skin excoriation, over a mean period of 6.7-month follow-up [3]. A study from Pena et al. showed that colostomy prolapse was observed in 119 (8\%) of the 1470 children and likewise in $16 \%$ concerning loop colostomy [8]. In a retrospective analysis of pediatric colostomies Nour et al. reported 19\% colostomy prolapse among 138 children [31]. The stoma formed in children are more prone to prolapse compared to adults [2]. The most commonly published incidence of stoma prolapse in children ranges from $8.1 \%$ to $25.6 \%$, median $18.8 \%$ [2] [3] [31] [37]-[39]. The incidence of stoma prolapse in pediatric patients is shown in Table 3 [3] [8] [31] [37]-[39]. 
Table 3. The incidence of stoma prolapse in pediatric patients (n). All are colostomy except our studies. (ARM anorectal malformation, HD Hirschsprung's Disease) [2] [3] [8] [31] [37]-[39].

\begin{tabular}{cccc} 
& $\mathbf{n}$ & Follow-up & Incidence\% \\
\hline Al-Salam et al. [37] & 74 & not stated & 18.9 \\
Chandler et al. [2] & 43 & not stated & 25.6 \\
Çiğdem et al. [3] & 473 & 6.7 months/mean(ARM/stoma closed) & 20.5 \\
& & 6.9 months/mean (HD) & \\
& & 3.6 months/mean (other indications) & 12 \\
Lister et al. [38] & 189 & not stated (old article) & 12 \\
Mollitt et al. [39] & 146 & $6-15$ months (closed/old article) & 18.8 \\
Nour et al. [31] & 138 & 10.7 - 12.4 months (ARM/HD) & 8.1 \\
Pena et al. [8] & 1470 & not stated & 4.6 \\
Our series/present study & 304 & (mostly HD/others) ileostomy and colostomy & \\
\hline
\end{tabular}

\subsection{Surgical Treatments of Stoma Prolapse}

A nonsurgical treatment by manual reduction seems to be an easy attempt, but recurrences are likely [40]. In case of persistence symptoms and/or vascular compromise of the prolapsed bowel, surgical intervention may be necessary. Both proximal and distal parts of the limbs of the stoma can prolapse, which can lead to ischemia of the stoma or of the extruded bowel. It is vital to acknowledge that the patient general quality of life can be relentlessly disadvantaged by a stoma, more especially stoma prolapse [5] [6] [30].

Significant amounts of patients with stoma prolapse including children require surgical correction. From Nour et al. 26 (19\%) of 138 children had colostomy prolapse of which 14 (54\%) needed surgical correction [31]. Pena et al. observed that, repair of the colostomy prolapse was needed in 91 (76\%) of the 119 children with colostomy prolapse of 1470 patients with stoma [8]. Several surgical techniques have been proposed to repair stoma prolapse, such as the purse string for temporary relief [7] [41]. Another technique, also for temporary correction of prolapsed stoma, depicted by Gauderer, involves the placement of a " $U$ " stitch from the lumen of the reduced bowel through the abdominal wall with a double armed needle [42]. Hata et al. used a staple device to correct stoma prolapsed [43] Figures 2(D)-(F).

A substitute technique to the one described by Hata et al. was recommended by Maeda et al. for prolapsed loop colostomies [28]. The surgical repair of stoma prolapse by a skin-grafted was first presented by Dragstedt [44]. The consequential firm stoma is invulnerable to prolapse, but it was disadvantaged my stenosis due to it rigid nature. Sohn et al. later revised the procedure, adding bidirectional myotomies over the last 2 inches of the bowel, upon which a meshed split-thickness skin graft is sutured to the serosa and to the peristomal skin [45].

$\mathrm{Ng}$ et al. observed, in pediatric patients the effect of distal colon securing in correct- 
ing prolapse of aloop colostomy. They employed a mathematical method with a length of mesentery secured to abdominal wall (L) $>3$ times the width (W) of the fascial aperture, they successfully showed that only few patients experienced prolapsed [17]. Though preventive, it could be employed during stoma prolapse repair. Abulafi et al. developed a version of the Delorme procedure for protruded colostomy [46].

Conversion of a prolapsed loop stoma to an end stoma using a local technique could be a way to go to correcting a loop prolapse. As already mentioned, end stoma carries a lower prolapse and recurrence rate [11] [12]. The prolapsed distal limb is separated entirely and closed with sutures or stapling machine. The stoma is transformed as an end stoma, the distal limb, if any remaining (or if not proctosigmoidectomy/Hartmann's procedure) is placed within the peritoneal cavity or as a double-barrel end stoma; with the distal closed end flushed at the skin level. Ein recommended a divided loop colostomy in infants and children [47] Figures 3(A)-(E).

The distal limb of a loop stoma is particularly at risk for prolapse, especially in Hirschsprung's disease patients [2] [47]. Similarly, Riaz et al. suggested an alternative to loop and end stomas for defunctioning the distal colon: the split transverse colostomy [48]. This procedure, also preventive, could be used as a reparative in event of recurrent stoma prolapse. Other surgical reparative procedures that may help halt recurrence of stoma prolapse include local revision using sutures [49], stapling using non-cutting linear stapler such as the GIA stapler, after reducing part of the protruded bowel to desired [20] [50] length laparotomy revision without or with re-siting the stoma [2] [27], button-pexy fixation [51], and retroperitoneal tunnel route [14] [52] [53] (Figures $4(\mathrm{~A})-(\mathrm{C}))$.

\subsection{Results-Pediatric Patients Data at OUS-R}

Fourteen of the 304 children (4.6\%) at OUS-R experienced stoma prolapse during the period from 01. 01. 2001 to 29. 05. 2013. Five stomas were considered appropriate for closure, remaining 9 required surgical correction, of these 9 , were 4 girls and 5 boys, 5 ileostomies ( 2 girls: 3 boys) and 4 colostomies ( 2 boys: 2 girls).

Five of the patients had Hirschsprung's disease as the indication for the stoma formation, 1 patient had acute lymphoblastic leukemia with colon perforation, 1 gastroschisis with colonic atresia, 1 necrotizing enterocolitis (NEC) with colonic perforation and 1 patient had gastrointestinal dysmotility with constipation. The median age at stoma formation was 1.7 years, ranging from 3 days to 5.7 years, the median weight at stoma formation was $12 \mathrm{~kg}$ ranging from $2.1 \mathrm{~kg}$ to $19 \mathrm{~kg}$.

To surgically repair stoma prolapse, 10 stapling using non-cutting linear stapler such as the GIA stapler were performed on 6 patients, 6 local revisions with sutures on 4 patients, 2 laparotomy revisions were performed on 2 patients and 1 laparotomy with retroperitoneal tunnel on 1 patient. A total of 19 surgical procedures to correct stoma prolapse were performed on the 9 pediatric patients; median 2, range 1-9 operations/ patient.

Three of the 5 patients with Hirschsprung's disease (HD) did not experience recur- 


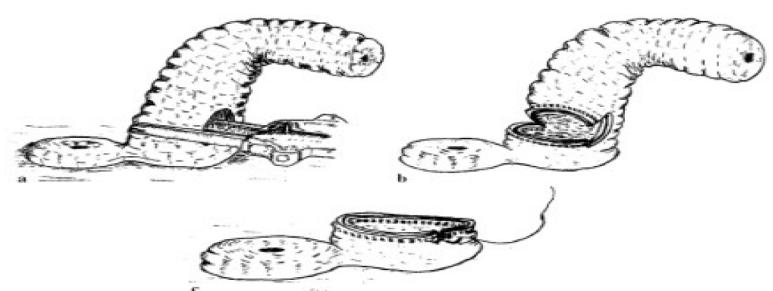

(A)
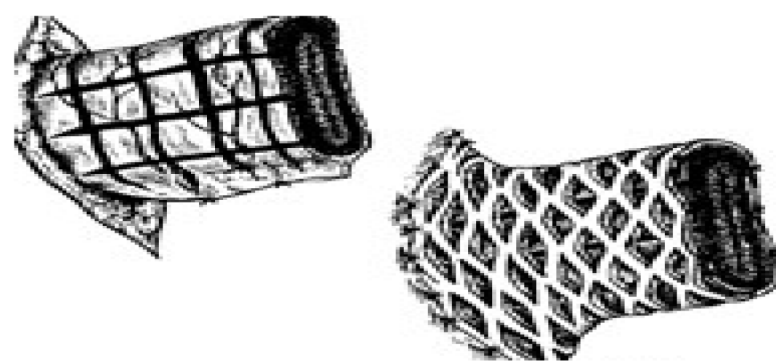

(B)

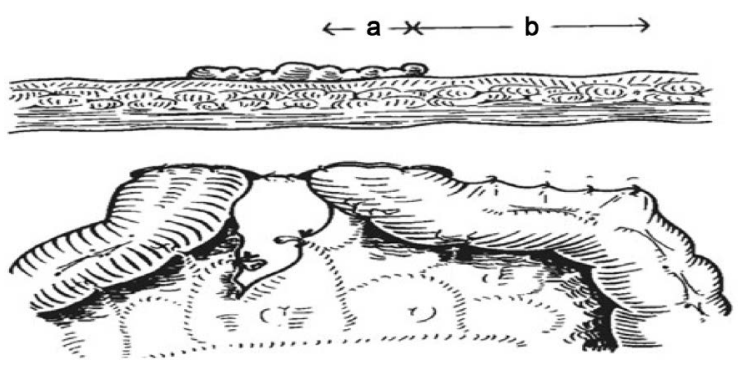

(C)
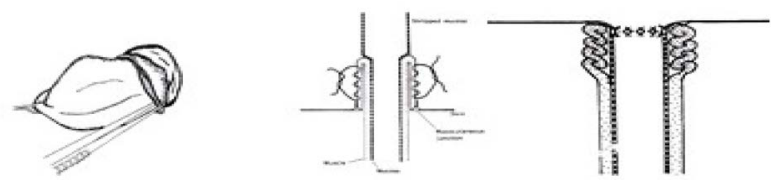

(D)

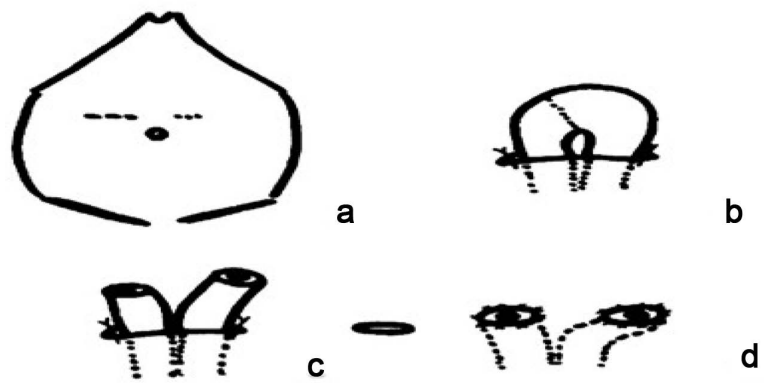

(E)

Figure 3. (A) Correction of a prolapsed loop colostomy. Maeda et al. [28]; (B) meshed split-thickness skin graft procedure. Sohn et al. [45]; (C) mesentery secured to abdominal wall (L) > 3times the width (W) of the fascial aperture. Ng et al. [17]; (D) modified delorme procedure for protruded colostomy. Abulafi et al. [46]; (E) Ein divided loop colostomy [47]. 


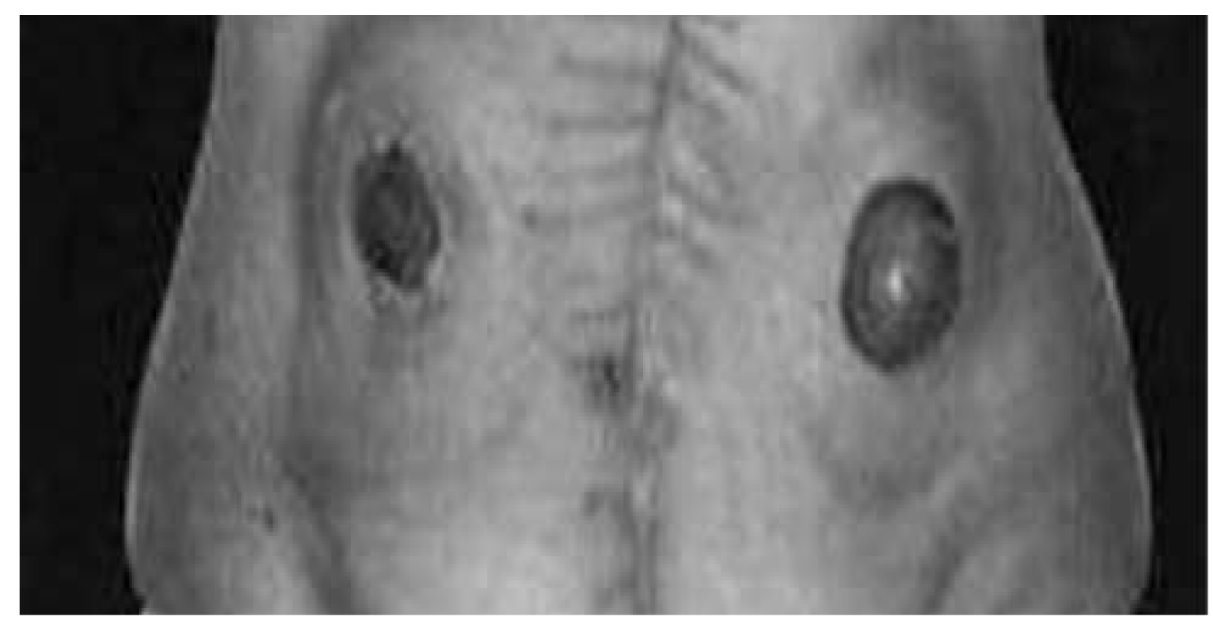

(A)

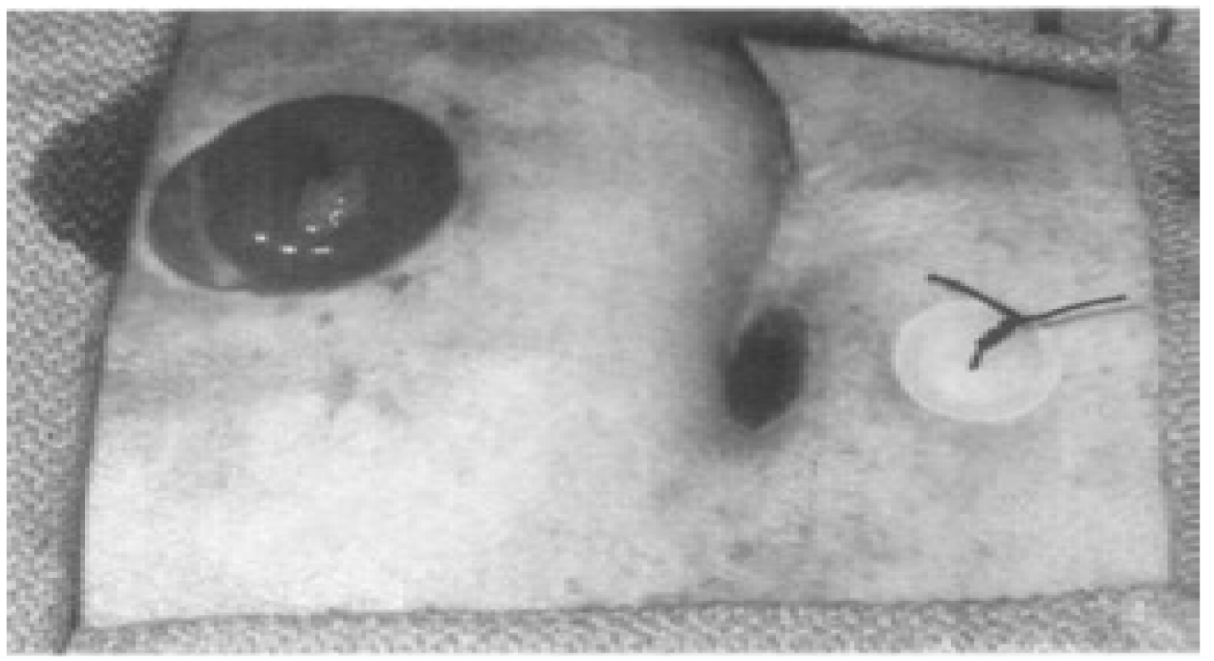

(B)

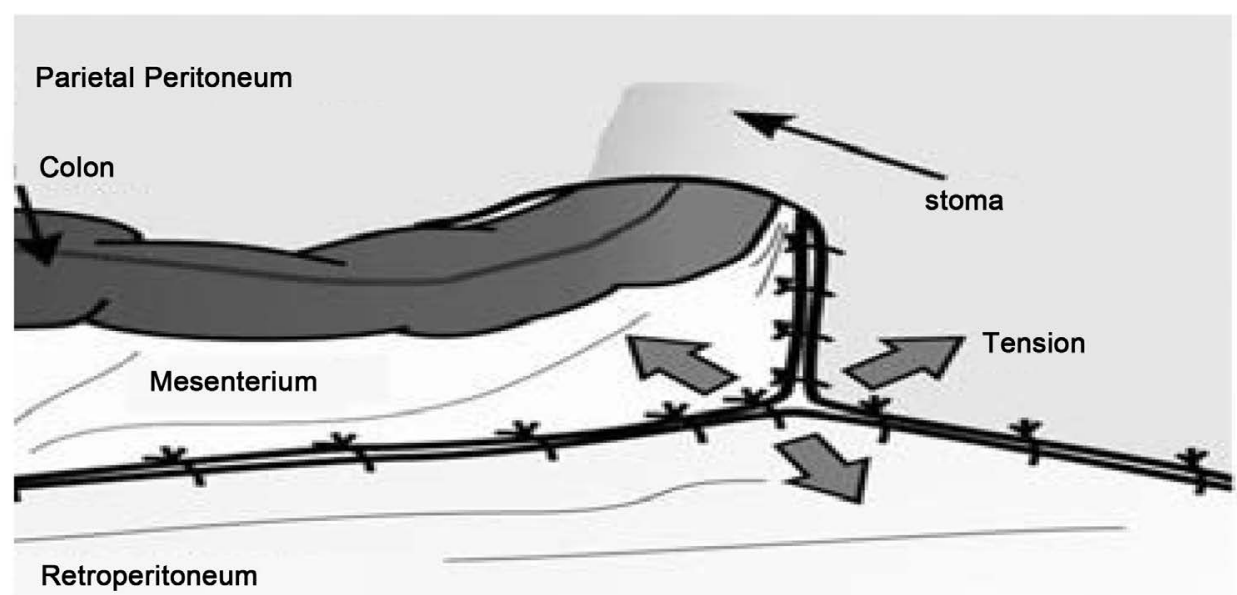

(C)

Figure 4. (A) The split transverse colostomy. Riaz et al. [48]; (B) button-pexy fixation procedure [51]; (C) retroperitoneal tunnel rute [53]. 
rence after surgical treatments; 2 underwent stapling, and 1 underwent local revision. Of the $2 \mathrm{HD}$ patients with recurrence, 1 underwent stapling, another 1 had laparotomy revision and laparotomy with retroperitoneal tunnel for bowel exit, in addition to the above mentioned surgical procedures, with recurrence in all. This was a difficult and problematic patient. The patient underwent a series of surgical operations to treat $\mathrm{Mb}$ Hirschsprung, affecting the entire colon leading to restorative proctocolectomy, with the creation of a well-functioning ileal pouch-anal anastomosis at the time of this study, waiting to close the stoma.

The patient with leukemia and colon perforation did not experience recurrence after local revision. The patient with gastroschisis and colonic atresia experienced recurrence after stapling.

The patient with NEC experienced recurrence on 2 occasions, after 2 local revisions with sutures. The patient with gastrointestinal dysmotility experienced recurrence after local revision with sutures, but did not experience recurrence after stapling.

Two of the 5 stomas with recurrence were closed early, other 3 underwent second or more surgical repair: For Nec patient, stoma was closed after another local revision was ineffective. For GD patient, stapling was effective after local revision proves ineffective. For the HD patient, none of the 4 surgical procedures was effective (some of the procedures were performed more than once), the stoma was later closed.

The mean time of stoma formation to the notice of prolapse for the 9 patients was 5 months. The median time of recurrence after the different types of surgical procedures was 3 months for the 5 patients who experienced recurrence. Seven of the 9 children subsequently underwent stoma closure. The time from stoma formation to closure or last medical record among the 9 patients ranges from 2 months to 7.8 years, median 2 years. A small sample size of 9 will not allow for statistical significant analysis.

The various indications for the stoma formation, types of surgical procedures, recurrences and other registered parameters are shown in Table 4 and Table 5.

\section{Discussion}

\subsection{Patients Data at OUS-R}

The creation of intestinal stoma is an important operation as the management of anorectal anomalies, Hirschsprung's disease and other conditions directly or indirectly affecting the bowel, in neonates, infants and children [2] [3] [54]. The median age of 1.7 years at stoma formation in this series is due to the fact that other methods of treatments were tried on most patients before stoma formation. The most common indication for stoma formation in this pediatric series was Hirschsprung's disease. This is similar to the literature [2]-[4] [31] [55].

As mentioned, the incidence of stoma prolapse in pediatric patients in the literature was reported to be around $8.1 \%$ - 25.6\%, median $18.8 \%$ [2] [3] [31] [37]-[39]. In our series, the observed incidence of stoma prolapse was $4.6 \%$, which is lower than most reported incidence of stoma prolapse in the pediatric medical literature. Eight of the $9 \mathrm{pa}$ tients in this series, experienced stoma prolapse as a late complication, which is com- 
Table 4. Patients characteristics with registered parameters and number (n).

\begin{tabular}{|c|c|}
\hline Underlying diagnosis & $\mathrm{n}$ \\
\hline Hirschsprung's disease & 5 \\
\hline Gastroschisis and colonic atresia & 1 \\
\hline Necrotizing enterocolitis & 1 \\
\hline Acute lymphoblastic leukemia (colon perforation) & 1 \\
\hline Gastrointestinal dysmotility & 1 \\
\hline Gender Male: Female (ileoeostmy: Colostomy) & $5: 4 \mathrm{M}(3: 2): \mathrm{F}(2: 2)$ \\
\hline Median age at stoma formation (range) & 1.7 years ( 3 days -5.7 years) \\
\hline Median weight (range) & $12 \mathrm{~kg}(2.1-19 \mathrm{~kg})$ \\
\hline Elective stoma & 6 \\
\hline Emergent stoma & 3 \\
\hline Temporary & 8 \\
\hline Permanent & 1 \\
\hline Recurrences of prolapse after first repair all method & 5 \\
\hline No recurrence & 4 \\
\hline Mean time of stoma formation to first prolapse & 5 months \\
\hline $\begin{array}{l}\text { Median follow-up period from stoma formation } \\
\text { to closure/last medical record (range) }\end{array}$ & 2 years ( 2 months -7.8 years) \\
\hline Total closed stoma during evaluation period/open stoma & 7:02 \\
\hline Colostomies & 4 \\
\hline left end sigmoid-Hirschsprung's disease (considering stoma closure) & 1 \\
\hline right end transverse-Hirschsprung's disease (stoma closed) & 1 \\
\hline left end transverse-Hirschsprung's disease (stoma closed) & 1 \\
\hline left loop sigmoid-colon perforation (stoma closed) & 1 \\
\hline Ileostomies & 5 \\
\hline right end-HD, GS (both stomas closed), GD (stoma not closed & 3 \\
\hline right loop-Hirschsprung's disease (stoma closed) & 1 \\
\hline end ileocolostomy-Nec (stoma closed) & 1 \\
\hline Total patients & 9 \\
\hline Total operations to repair prolapse and recurrence & $\begin{array}{c}19(\text { median }=2, \\
\text { range } 1-9 \text { operations/patient })\end{array}$ \\
\hline
\end{tabular}

Table 5. Reoperation to correct stoma prolapse without resiting of stoma. Number of stoma not the same as number of patients; some patients had the same procedures more than once, while others had different procedures.

\begin{tabular}{cccc}
\hline Type of procedure & $\begin{array}{c}\text { Number of } \\
\text { surgical procedure }\end{array}$ & $\begin{array}{c}\text { Number of } \\
\text { stoma employed on }\end{array}$ & Effect \\
\hline Stapling & 10 & 6 & $3 / 6(50 \%)$ \\
Local revision & 6 & 4 & $2 / 4(50 \%)$ \\
Laparotomy revision & 2 & 2 & none \\
Laparotomy with retroperitoneal tunnel & 1 & 13 stoma & none \\
Total surgical procedure & 19 &
\end{tabular}


parable to the literature [3] [10] [12] [13].

As cited earlier, significant amounts of children with stoma prolapse require surgical correction, ranging from $54 \%$ to $76 \%$ [8] [31]. In the present series, 9 of the 14 children (64\%) with stoma prolapse, required surgical intervention, which is comparable to the literature [8] [31].

Allen-Marsh et al. performed 20 local revisions for end colostomy prolapse on adults. About $55 \%$ of these local revisions was deemed unsuccessfully [49]. Similarly, 4 patients in this series underwent surgical repair of prolapse with sutures using local revision procedure, 1 end transverse, 1 loop sigmoid, 1 loop ileostomy and 1 end ileostomy. Prolapse re-occurred in 2 ( 1 end transverse and 1 end ileostomy) of the 4 patients (50\%).

The non-cutting linear stapling technique was performed on 6 pediatric patients with stoma prolapse in this series, 1 end sigmoid, 3 end ileostomies and 2 end transverse colostomies with recurrence in 3 patients (50\% success); 2 end transverse and 1 end ileostomy. Ecker et al. reported no occurrence of stoma prolapse among the 9 adults patients with end ileostomy treated with the stapling [50].

Failure of an extra-abdominal surgical procedure may be followed by a laparotomy revision without or with re-siting of the stoma. Chandler et al. unsuccessfully treated 1 adult patient with unspecified colostomy prolapse, using a laparotomy procedure, by securing the intestine to the parietal peritoneum [2]. Similar to the literature, 2 patients in the present series unsuccessfully underwent laparotomy revision with bowel fixation to the abdominal wall; prolapse re-occurred in both, 1 end transverse and 1 end ileostomy. The stoma should however, be resitedif the original stoma site is not within the rectus muscle [13]. The stoma should also be resited if the original site is infected; the new site without scar and fibrosis may provide stronger supporting structures. Stoma prolapse is in effect an intussusception [41]. Thus, laparotomy with bowel fixation may be appropriate for a sliding type of stoma prolapse, especially when an extra-abdominal procedure proves futile.

One patient with right end transverse colostomy prolapse in this series of 9 patients was surgically treated by laparotomy with retroperitoneal tunnel for bowel exit. The procedure was not successful, as the patient experienced recurrence after 6 months; prolapse re-occurred in $1 / 1$ and 4/8 for extraperitoneal and intraperitoneal routes respectively (stoma types of the other 8 intraperitoneal group is shown in Table 4). Similarly, Londono-Schimmer et al. revealed that the extraperitoneal procedure did not reduce the rate of prolapse. In their study of 203 adults number with a permanent end colostomy, prolapse occurred in 5\% and 7\% for the intraperitoneal and the extraperitoneal routes respectively $(p>0.5)$ [14]. However, Whittaker et al. observed some success with the retroperitoneal surgical procedure, when they compare the complications of intraperitoneal and retroperitoneal end colostomies in adults patients which revealed a significantly higher frequency of prolapse in the intraperitoneal group $(p<0.1)$ [52].

Similarly, in another study of 150 adults patients with an end ileostomy, Leong et al. also observed success with the retroperitoneal method when they reported that none of 
the 3 retroperitoneal stomas developed prolapse [14]. A study of surgeons, however, showed that only $13 \%$ performed this surgical procedure in 1985 [56]. This may be due to the fact that, the technique is underemphasize in surgical training programs [56].

\subsection{Literature}

Krasna repaired end colostomy prolapse by the purse string method. He observed no recurrence of the unspecified colostomy prolapse, the number of patients were also not specified [41]. Golladay et al. incorporated the procedure during construction of 85 intestinal end loop stomain children; 40 small bowel enterostomies and 45 colostomies with no instances of prolapse [7].

However, if the purse string procedure is used in permanent stomas, the fixed sutures may lead to stenosis as the child grows. Hence, the procedure is appropriate for temporary stoma.

Cory reported success in the 4 patients he surgically treated for end colostomy prolapse and transverse loop colostomy prolapse with the modified purse string procedure, the patients did not experience prolapse over 1 year follow up period, the number of prolapse for each stoma type were not specified [57]. However, a single suture should be placed around both the proximal and distal limbs of the loop stoma, so as to avoid ischaemia of the proximal bowel which might occur if the suture is placed around the proximal limb alone. This also prevents prolapse of the distal limb of the stoma [57].

Thus, these "spot sewing" techniques from both Krasna and Cory are worthy of recommendation, especially the much tested and proven purse string method. Though, the sample size from Cory is small for any proper statistical deductions, it could be appropriate for further research.

The U-stitch was described earlier as one of methods that could be used to repair stoma prolapse. Gauderer et al. performed the procedure on 4 children with stoma prolapse, 2 with loop colostomies, 1 with a loop colostomy with a skin bridge, and 1 with two separate stomas, the prolapse was successfully reduced in all the 4 children [42]. Care must be taken not to tighten sutures excessively, because this can lead to skin erosion beneath the button. Sutures and bolsters could be removed when adhesions are established [42].

Hata et al. reported using linear stapling cutter device described above on 5 adults patients with no recurrence of stoma prolapse, 4 end colostomies, and 1 end ileostomy and end colostomy, though the procedure was performed only for stoma prolapse of end colostomies [43]. Maeda et al. also reported no recurrence of loop transverse stoma prolapse in the 2 adults patients treated with a substitute technique to the one described by Hata et al. also described above [28]. However, if stapling with linear cutter is used in pediatric patient, especially neonates and infants, one would like to reduce part of the protruded bowel back in to the abdominal cavity without or with minimal resection of the bowel, so as not to deprive the child of an important part of intestine (ileum) for absorption.

Sohn et al. reported that, one adult patient who underwent skin graft with the revised bidirectional seromyotomies procedure experienced no recurrence of the end ileostomy 
prolapse as well as no stoma stenosis after a 3-year follow-up [45].

According to Canil et al. all of the 6 children with stoma prolapse in their studies were successfully repaired with the button-pexy method mentioned above, 1 patient had ileal mucous fistula prolapse which was surgically corrected. Stoma type of the other 5 were not specified [51].

Abulafi et al. achieved good results with the described modified Delorme's procedure in 2 patients, 1 with prolapsed end colostomy and another 1 with prolapsed of both limbs of transverse loop colostomy, during 3 years of follow-up [46].

The above mentioned surgical procedures have the benefit of being extra-abdominal, operation time is normally not lengthy, recovery time is quick, leading to shorter length of stay in hospital (most of the procedures could be done as an outpatient surgery), no massive revisions, there is fewer chance of complications by not performing a laparotomy or a more invasive surgical procedure, the methods are relatively easier to use, safer and cost-effective compared to laparotomy, and are suitable procedures for fixed stoma prolapse; end stoma as well as other stoma prolapse which are fixed. Furthermore, the procedures should be considered in neonates, (elderly) and patients in poor condition, not suitable for a more invasive surgery.

$\mathrm{Ng}$ et al. observed using the tethering surgical procedure described above that in a sample of 55 pediatric patients with loop colostomy, only few patients experienced prolapse compared to patients without fixation (7 and 26\%, respectively) [17].

The rodless end-loop stoma was introduced as a complementary to the more traditional loop stoma. Two-hundred and twenty-nine patients had rodless end-loop stomas constructed at the University of Illinois, ranging from 3 to 7 years; only 1 patient reported prolapse (0.4\%) [29]. Though preventive, in the case of recurrent stoma prolapse, the above mentioned 2 surgical procedures may be appropriate reparative surgical procedures for stoma prolapse.

Cheung reported a rate of $47 \%$ prolapse, in a series of 19 loop transverse colostomies; in contrast, only 1 of the 6 bridge transverse colostomies, in which the proximal and distal limbs were drawn through separate fascial incisions were affected by prolapse [12]. Of the 13 pediatric patients who underwent the divided transverse loop colostomy surgical procedure described by Ein, none experienced stoma prolapse over a follow-up of up to 3 years [47]. Similarly, Chandramouli et al. published that 2 loop colostomy prolapses were repaired successfully by resection of the prolapsing segments, with reconstruction of the colostomies in the same location but separating the 2 limbs by a fascial bridge [9].

The split transverse colostomy, constructed by Riaz et al. in 24 adults was found to have significantly fewer total complications including prolapse as compared to the traditional loop transverse colostomy undertaken in 25 patients $(p<0.05)$ during the study period; these patients had a much lower incidence of complications such as prolapse, parastomal hernias, bleeding and retraction compared with patients with either loop transverse colostomies or loop ileostomies [48].

Thus, the tethering surgical procedure, the rodless end-loop, skin-bridge, divided 
loop and split transverse, are appropriate surgical methods for reducing the prolapse and recurrence rate in a loop stoma, especially when less invasive surgical procedures have not been successful.

Unlike transverse colostomies, sigmoid colostomies have been reported to have less stoma prolapse and recurrence rate [3] [12] [31]. This is in contrast to Pena et al. who postulated that transverse and sigmoid are mobile part of the colon, hence prone to prolapse and recurrence after surgical treatment [8]. This ambiguity may be due to the fact that sigmoid is easy to manage in terms of surgical repair with, for example inverted $\mathrm{v}$-shaped mesenteric peritoneal fold that attaches the sigmoid colon to the pelvic wall, and with bowel fixation to the peritoneum. Furthermore, according to Pena et al. the mobile sigmoid adjoining the descending colon which is usually connected to the left retroperitoneum, should be attached to abdominal wall [8]. The authors have suggested that, if the fixed colon forms the proximal stoma, the patient will not experience stoma prolapse of that limb. Constructing the distal sigmoid limb, as a tiny and flat mucus fistula during stoma formation or during repair of a stoma prolapse when possible, will help reduce the rate of stoma prolapse and recurrence [8]. Likewise, from above, using the fixed portion of the colon, such as the descending colon, for both the proximal and the distal limbs when possible during stoma formation or repair of stoma prolapse, may also help reduce the rate of stoma prolapse and recurrence.

\subsection{Limitations}

Disparity in study design; retrospective contra prospective, limited sample size, inclusion and exclusion criteria, endpoint classifications, variation in follow up duration, temporary contra permanent stoma, likely publication bias, diversity in patient characteristics, scarcity of recent and high quality studies, failure of some authors to specify the type of stoma and the number of patients, are possible limitations that might have affected this thesis. Another limitation is that the data sample size of 9 in the current series, would not allow for statistical significant analysis. Surgical procedures in the current series and in the literature remain unproven in large studies. The etiology and mechanism for various stoma prolapse have not been comprehensively mentioned or defined in the literature. Hence, making it difficult to discuss, evaluate properly, and to compare the effect of the surgical treatments.

Operating services may also play a role in stoma prolapse and recurrences after surgical treatment. All the patients in the present series were operated at the pediatric surgical ward by pediatric surgeons, compared to adults population in the literature where surgeons with different specialties may be involved in formation of stoma and surgical repair of stoma prolapse. Park et al. observed a low rate of complications including stoma prolapse among trauma team, though nonsignificant difference [10]. To the best of my knowledge, most of the surgical procedures used in the present pediatric series were tried mostly on adults in the literature. The publications of similar surgical procedures in children are scarce, further weakening the comparison between the present series and the literature. But, despite these apparent limitations, this thesis contains useful information that can be used to surgically reduce the incidence of stoma prolapse 
and recurrence.

\section{Conclusions}

Unlike adults, gastrointestinal stoma in neonates, infants and children is usually temporary. Stoma formation is a common operative procedure done on children. Stoma formation may be lifesaving and important to maintain a child's well-being and health. A stoma prolapse is one of the late and major complications of stoma. Surgical operation to repair the prolapse of a stoma is recommended if its poses problems, affect the quality of life, and when conservative methods have failed. Neither the extra-abdominal nor the intra-abdominal surgical methods have been proven superior to one another from both the literature and the present study, though the number of studied patients are limited. But, due to the invaginating nature of the stoma prolapse, an intra-abdominal surgical procedure which best addresses intestinal and/or mesentery fixation may be the best surgical repair method for sliding stoma prolapse, especially when an extraabdominal procedure proves futile. A fixed stoma prolapse can be repaired by a local surgical procedure [24].

In general, unlike other stoma complications, stoma prolapse is known to be associated with an increased risk of recurrence following surgical repair [47] [49]. It may indeed seem that the greater the number of surgical treatments we have for a complication such as stoma prolapse, the less we know about the most effective surgical technique to remedy it. The very fact that so many surgical procedures have been described to correct stoma prolapse, attest to lack of sole superiority of any single procedure. Even a well constructed stoma does not completely remove the risk of prolapse. Thus preferably, when possible, closure of stoma should be done as soon as possible. Incidence of stoma prolapse in our series of pediatric patients, during the period 2001-2013 is lower than most reported incidence in the pediatric medical literature.

\section{Acknowledgements}

Thanks to Harald Langeggen senior consultant surgeon and Egil Johnson senior consultant surgeon and professor II, department of gastric and pediatric surgery, Oslo University Hospital. Both of whom have meticulously read through, advised and corrected me. Any remaining errors, if at all, are mine.

\section{References}

[1] Dinnick, T. (1934) The Origins and Evolution of Colostomy. British Journal of Surgery, 22, 142-154. http://dx.doi.org/10.1002/bjs.1800228516

[2] Chandler, J.G. and Evans, B.P. (1978) Colostomy Prolapse. Surgery, 84, 577-582.

[3] Cigdem, M.K., Onen, A., Duran, H., Ozturk, H. and Otcu, S. (2006) The Mechanical Complications of Colostomy in Infants Andchildren: Analysis of 473 Cases of a Single Center. Pediatric Surgery International, 22, 671-676. http://dx.doi.org/10.1007/s00383-006-1718-4

[4] Lau, J.T. (1983) Proximal end Transverse Colostomy in Children. A Method to Avoid Colostomy Prolapse in Hirschsprung's Disease. Diseases of the Colon \& Rectum, 26, 221-222. http://dx.doi.org/10.1007/BF02562481 
[5] Brown, H. and Randle, J. (2005) Living with a Stoma: A Review of the Literature. Journal of Clinical Nursing, 14, 74-81. http://dx.doi.org/10.1111/j.1365-2702.2004.00945.x

[6] Gooszen, A.W., Geelkerken, R.H., Hermans, J., Lagaay, M.B. and Gooszen, H.G. (2000) Quality of Life with a tEmporary Stoma: Ileostomy vs. Colostomy. Diseases of the Colon \& Rectum, 43, 650-655. http://dx.doi.org/10.1007/BF02235581

[7] Golladay, E.S., Bernay, F. and Wagner, C.W. (1990) Prevention of Prolapse in Pediatric Enterostomas with Purse String Technique. Journal of Pediatric Surgery, 25, 990-991. http://dx.doi.org/10.1016/0022-3468(90)90244-4

[8] Pena, A., Migotto-Krieger, M. and Levitt, M.A. (2006) Colostomy in Anorectal Malformations: A Procedure with Serious but Preventable Complications. Journal of Pediatric Surgery, 41, 748-756. http://dx.doi.org/10.1016/j.jpedsurg.2005.12.021

[9] Chandramouli, B., Srinivasan, K., Jagdish, S. and Ananthakrishnan, N. (2004) Morbidity and Mortality of Colostomy and Its Closure in Children. Journal of Pediatric Surgery, 39, 596-599. http://dx.doi.org/10.1016/j.jpedsurg.2003.12.016

[10] Park, J.J., Del Pino, A., Orsay, C.P., Nelson, R.L., Pearl, R.K., Cintron, J.R., et al. (1999) Stoma Complications: the Cook County Hospital Experience. Diseases of the Colon \& Rectum, 42, 1575-1580. http://dx.doi.org/10.1007/BF02236210

[11] Shabbir, J. and Britton, D.C. (2010) Stoma Complications: A Literature Overview. Colorectal Disease, 12, 958-964. http://dx.doi.org/10.1111/j.1463-1318.2009.02006.x

[12] Cheung, M.T. (1995) Complications of an Abdominal Stoma: An Analysis of 322 Stomas. Australian and New Zealand Journal of Surgery, 65, 808-811. http://dx.doi.org/10.1111/j.1445-2197.1995.tb00566.x

[13] Fleshman, J.W. and Lewis, M.G. (2007) Complications and Quality of Life after Stoma Surgery: A Review of 16,470 Patients in the UOA Data Registry. Seminars in Colon and Rectal Surgery, 18, 19-24. http://dx.doi.org/10.1053/j.scrs.2006.12.006

[14] Leong, A.P., Londono-Schimmer, E.E. and Phillips, R.K. (1994) Life-Table Analysis of Stomal Complications Following Ileostomy. British Journal of Surgery, 81, 727-729. http://dx.doi.org/10.1002/bjs.1800810536

[15] Harris, D.A., Egbeare, D., Jones, S., Benjamin, H., Woodward, A. and Foster, M.E. (2005) Complications and Mortality Following Stoma Formation. Annals of the Royal College of Surgeons of England, 87, 427-431. http://dx.doi.org/10.1308/003588405X60713

[16] Ripoche, J., Basurko, C., Fabbro-Perray, P. and Prudhomme, M. (2011) Parastomal Hernia. A Study of the French Federation of Ostomy Patients. Journal of Visceral Surgery, 148, e435-e441. http://dx.doi.org/10.1016/j.jviscsurg.2011.10.006

[17] Bass, E.M., Del Pino, A., Tan, A., Pearl, R.K., Orsay, C.P. and Abcarian, H. (1997) Does Preoperative Stoma Marking and Education by the Enterostomal Therapist Affect Outcome? Diseases of the Colon \& Rectum, 40, 440-442. http://dx.doi.org/10.1007/BF02258389

[18] Nastro, P., Knowles, C.H., McGrath, A., Heyman, B., Porrett, T.R. and Lunniss, P.J. (2010) Complications of Intestinal Stomas. British Journal of Surgery, 97, 1885-1889. http://dx.doi.org/10.1002/bjs.7259

[19] Robertson, I., Leung, E., Hughes, D., Spiers, M., Donnelly, L., Mackenzie, I., et al. (2005) Prospective Analysis of Stoma-Related Complications. Colorectal Disease, 7, 279-285. http://dx.doi.org/10.1111/j.1463-1318.2005.00785.x

[20] Nwomeh, B.C. (2008) Reoperation for Stoma Complications. In: Steven Teich, M.D., Donna, A. and Caniano, M.D., Eds., Reoperative Pediatric Surgery, Humana Press, Clifton, 279285. http://dx.doi.org/10.1007/978-1-60327-071-7_16

[21] Shellito, P.C. (1998) Complications of Abdominal Stoma Surgery. Diseases of the Colon \& 
Rectum, 41, 1562-1572. http://dx.doi.org/10.1007/BF02237308

[22] Arumugam, P.J., Bevan, L., Macdonald, L., Watkins, A.J., Morgan, A.R., Beynon, J., et al. (2003) A Prospective Audit of Stomas-Analysis of Risk Factors and Complications and Their Management. Colorectal Disease, 5, 49-52. http://dx.doi.org/10.1046/j.1463-1318.2003.00403.x

[23] Cottam, J., Richards, K., Hasted, A. and Blackman, A. (2007) Results of a Nationwide Prospective Audit of Stoma Complications within 3 Weeks of Surgery. Colorectal Disease, 9, 834-838. http://dx.doi.org/10.1111/j.1463-1318.2007.01213.x

[24] Goldblatt, M.S., Corman, M.L., Haggitt, R.C., Coller, J.A. and Veidenheimer, M.C. (1977) Ileostomy Complications Requiring Revision: Lahey Clinic Experience, 1964-1973. Diseases of the Colon \& Rectum, 20, 209-214. http://dx.doi.org/10.1007/BF02587180

[25] Kim, J.T. and Kumar, R.R. (2006) Reoperation for Stoma-Related Complications. Clinics in Colon and Rectal Surgery, 19, 207-212. http://dx.doi.org/10.1055/s-2006-956441

[26] Pomeranz, A.A. (1963) An Operation for Prevention of Ileostomy Prolapse. Diseases of the Colon \& Rectum, 6, 381-384. http://dx.doi.org/10.1007/BF02618402

[27] Weaver, R.M., Alexander-Williams, J. and Keighley, M.R. (1988) Indications and Outcome of Reoperation for Ileostomy Complications in Inflammatory Bowel Disease. International Journal of Colorectal Disease, 3, 38-42. http://dx.doi.org/10.1007/BF01649682

[28] Maeda, K., Maruta, M., Utsumi, T., Sato, H., Masumori, K. and Aoyama, H. (2003) Pathophysiology and Prevention of Loop Stomal Prolapse in the Transverse Colon. Techniques in Coloproctology, 7, 108-111. http://dx.doi.org/10.1007/s10151-003-0020-x

[29] Stevenson, J.K. and Volwiler, W. (1971) Ileostomy Stoma Complications-Prevention and Correction. Surgery Annual, 3, 305-322.

[30] McErlain, D., Kane, M., McGrogan, M. and Haughey, S. (2004) Prolapsed Stoma. Nursing Standard, 18, 41-42. http://dx.doi.org/10.7748/ns2004.01.18.18.41.c3526

[31] Nour, S., Beck, J. and Stringer, M.D. (1996) Colostomy Complications in Infants and Children. Annals of the Royal College of Surgeons of England, 78, 526-530.

[32] Garcia-Botello, S.A., Garcia-Armengol, J., Garcia-Granero, E., Espi, A., Juan, C., LopezMozos, F., et al. (2004) A Prospective Audit of the Complications of Loop Ileostomy Construction and Takedown. Digestive Surgery, 21, 440-446. http://dx.doi.org/10.1159/000083471

[33] Edwards, D.P., Leppington-Clarke, A., Sexton, R., Heald, R.J. and Moran, B.J. (2001) Stoma-Related Complications Are More Frequentafter Transverse Colostomy than Loop Ileostomy: A Prospective Randomized Clinical Trial. British Journal of Surgery, 88, 360363. http://dx.doi.org/10.1046/j.1365-2168.2001.01727.x

[34] Law, W.L., Chu, K.W. and Choi, H.K. (2002) Randomized Clinical Trial Comparing Loop Ileostomy and Loop Transverse Colostomy Forfaecal Diversion Following Total Mesorectal Excision. British Journal of Surgery, 89, 704-708.

http://dx.doi.org/10.1046/j.1365-2168.2002.02082.x

[35] Hoffman, M.S., Barton, D.P., Gates, J., Roberts, W.S., Fiorica, J.V., Finan, M.A., et al. (1992) Complications of Colostomy Performed on Gynecologic Cancer Patients. Gynecologic Oncology, 44, 231-234. http://dx.doi.org/10.1016/0090-8258(92)90048-N

[36] Garlock, J.H. and Kirschner, P.A. (1957) The Prevention of Ileostomy Dysfunction: A Modification of Technique. Surgery, 42, 765-766.

[37] Al-Salem, A.H., Grant, C. and Khawaja, S. (1992) Colostomy Complications in Infants and Children. International Surgery, 77, 164-166. 
[38] Lister, J., Webster, P.J. and Mirza, S. (1983) Colostomy Complications in Children. Practitioner, 227, 229-237.

[39] Mollitt, D.L., Malangoni, M.A., Ballantine, T.V. and Grosfeld, J.L. (1980) Colostomy Complications in Children: An Analysis of 146 Cases. Archives of Surgery, 115, 455-458. http://dx.doi.org/10.1001/archsurg.1980.01380040079014

[40] Fucini, C. (1989) A Simple Device for Prolapsing Loop Colostomies. Diseases of the Colon and Rectum, 32, 534-535. http://dx.doi.org/10.1007/BF02554514

[41] Krasna, I.H. (1979) A Simple Purse String Suture Technique for Treatment of Colostomy Prolapse and Intussusception. Journal of Pediatric Surgery, 14, 801-802.

http://dx.doi.org/10.1016/S0022-3468(79)80269-9

[42] Gauderer, M.W. and Izant Jr., R.J. (1985) A Technique for Temporary Control of Colostomy Prolapse in Children. Journal of Pediatric Surgery, 20, 653-655. http://dx.doi.org/10.1016/S0022-3468(85)80017-8

[43] Hata, F., Kitagawa, S., Nishimori, H., Furuhata, T., Tsuruma, T., Ezoe, E., et al. (2005) A Novel, Easy, and Safe Technique to Repaira Stoma Prolapse Using a Surgical Stapling Device. Digestive Surgery, 22, 306-310. http://dx.doi.org/10.1159/000088626

[44] Dragstedt, L.R., Dack, G.M. and Kirsner, J.B. (1941) Chronic Ulcerative Colitis: A Summary of Evidence Implicating Bacterium Necrophorum as an Etiologic Agent. Annals of Surgery, 114, 653-662. http://dx.doi.org/10.1097/00000658-194110000-00011

[45] Sohn, N., Schulman, N., Weinstein, M.A. and Robbins, R.D. (1983) Ileostomy Prolapse Repair Utilizing Bidirectional Myotomy and Ameshed Split-Thickness Skin Graft. American Journal of Surgery, 145, 807-808. http://dx.doi.org/10.1016/0002-9610(83)90146-0

[46] Abulafi, A.M., Sherman, I.W. and Fiddian, R.V. (1989) Delorme Operation for Prolapsed Colostomy. British Journal of Surgery, 76, 1321-1322. http://dx.doi.org/10.1002/bjs.1800761234

[47] Ein, S.H. (1984) Divided Loop Colostomy That Does Not Prolapse. American Journal of Surgery, 147, 250-252. http://dx.doi.org/10.1016/0002-9610(84)90100-4

[48] Riaz, A.A. and Thompson, H.H. (2006) Split Transverse Colostomy: An Alternative Method of Defunctioning the Distal Colon. Techniques in Coloproctology, 10, 57-60. http://dx.doi.org/10.1007/s10151-006-0253-6

[49] Allen-Mersh, T.G. and Thomson, J.P. (1988) Surgical Treatment of Colostomy Complications. British Journal of Surgery, 75, 416-418. http://dx.doi.org/10.1002/bjs.1800750507

[50] Ecker, K.W., Schmid, T., Xu, H.S. and Feifel, G. (1992) Improved Stabilization of Conventional (Brooke) Ileostomies with the Stapler Technique. World Journal of Surgery, 16, 525529. http://dx.doi.org/10.1007/BF02104461

[51] Canil, K., Fitzgerald, P., Lau, G., Cameron, G. and Walton, M. (1995) Button-Pexy Fixation for Repair of Ileostomy and Colostomy Prolapse. Journal of Pediatric Surgery, 30, 11481149. http://dx.doi.org/10.1016/0022-3468(95)90008-X

[52] Whittaker, M. and Goligher, J.C. (1976) A Comparison of the Results of Extraperitoneal and Intraperitoneal Techniques for Construction of Terminal Iliac Colostomies. Diseases of the Colon \& Rectum, 19, 342-344. http://dx.doi.org/10.1007/BF02590931

[53] Yokoyama, Y., Kawai, K., Kazama, S., Yoneyama, S., Tanaka, J., Tanaka, T., et al. (2014) A Case of Extraperitoneal Stoma-Associated Internal Hernia after Abdominoperineal Resection. World Journal of Surgical Oncology, 12, 141. http://dx.doi.org/10.1186/1477-7819-12-141

[54] Macmahon, R.A., Cohen, S.J. and Eckstein, H.B. (1963) Colostomies in Infancy and Childhood. Archives of Disease in Childhood, 38, 114-117. 
http://dx.doi.org/10.1136/adc.38.198.114

[55] Ekenze, S.O., Agugua-Obianyo, N.E.N. and Amah, C.C. (2007) Colostomy for Large Bowel Anomalies in Children: A Case Controlled Study. International Journal of Surgery, 5, 273 277. http://dx.doi.org/10.1016/j.ijsu.2007.01.008

[56] Pearl, R.K., Prasad, M.L., Orsay, C.P., Abcarian, H. and Tan, A.B. (1985) A Survey of Technical Considerations in the Construction of Intestinal Stomas. American Journal of Surgery, 51, 462-465.

[57] Corry, M. (1984) Colostomy Prolapse. British Journal of Surgery, 71, 81. http://dx.doi.org/10.1002/bjs.1800710130 


\section{Appendix: Patients Registration Form}

Indication for stoma

underlying diagnosis

age/weight at stoma formation

$\mathrm{Kg}$

days/wks./mths/yrs.

boy

girl

\section{Stoma}

end

loop

divided

permanent ( $>6 \mathrm{mths})$

temporary

indefinite

colostomy: descendens /sigmoid

transverse

ascendens

ileostomy

jejunostomy

emergent

elective

stoma in the right iliac fossa

in left iliac fossa other location

within rectus $\mathrm{m}$. not within rectus $\mathrm{m}$.

unknown

preoperative marking yes unknown

no

\section{Prolapse}

time from stoma formation to prolapse

procedure for repair: stapling

local revision__laparotomy__ other

\section{Prolapse}

time from repair of prolapse to new prolapse

procedure for repair: stapling

local revision laparotomy other

\section{Prolapse}

time from repair of prolapse to new prolapse procedure for repair: stapling local revision laparotomy other

if closure of stoma, time from recurrence of prolapse after repair to stoma closure

if closure of stoma, time from repair of prolapse without occurrence to stoma closure time from last repair of stoma prolapse without recurrence to last medical record until today

time from last recurrence until last medical record

until today

further plan of action if any 


\section{Abbreviations}

ASIS: Anterio superior iliac spine

ARM: Anorectal malformation

GD: Gastrointestinal dysmotility

GS: Gastroschisis

HD: Hirschsprung's disease

F: Female

M: Male

NEC: Necrotizing enterocolitis

OUS-R: Oslo University Hospital-The National Hospital (Oslo Universitetssykehus Rikshospitalet)

DIPS: Electronic journal system at OUS-R

Submit or recommend next manuscript to SCIRP and we will provide best service for you:

Accepting pre-submission inquiries through Email, Facebook, LinkedIn, Twitter, etc. A wide selection of journals (inclusive of 9 subjects, more than 200 journals)

Providing 24-hour high-quality service

User-friendly online submission system

Fair and swift peer-review system

Efficient typesetting and proofreading procedure

Display of the result of downloads and visits, as well as the number of cited articles

Maximum dissemination of your research work

Submit your manuscript at: http://papersubmission.scirp.org/

Or contact ss@scirp.org 